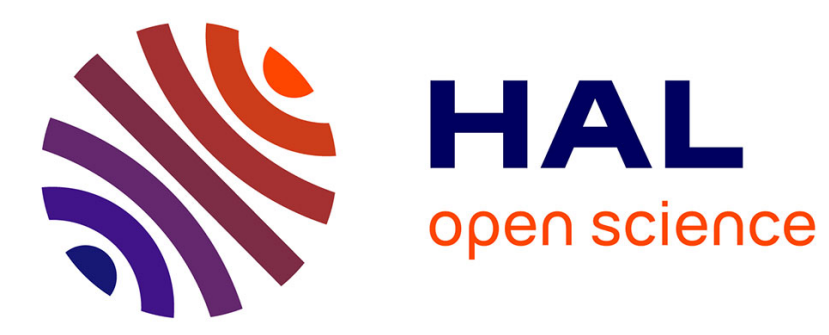

\title{
NUMERICAL SIMULATION OF THE CHARGE STATE EVOLUTION AND ENERGY LOSSES IN HEAVY ION BEAM-PLASMA INTERACTIONS
}

J. Guihaumé, R. Dei-Cas, M. Beuve, S. Joly

\section{- To cite this version:}

J. Guihaumé, R. Dei-Cas, M. Beuve, S. Joly. NUMERICAL SIMULATION OF THE CHARGE STATE EVOLUTION AND ENERGY LOSSES IN HEAVY ION BEAM-PLASMA INTERACTIONS. Journal de Physique Colloques, 1988, 49 (C7), pp.C7-123-C7-132. 10.1051/jphyscol:1988714 . jpa-00228198

\section{HAL Id: jpa-00228198 https://hal.science/jpa-00228198}

Submitted on 1 Jan 1988

HAL is a multi-disciplinary open access archive for the deposit and dissemination of scientific research documents, whether they are published or not. The documents may come from teaching and research institutions in France or abroad, or from public or private research centers.
L'archive ouverte pluridisciplinaire HAL, est destinée au dépôt et à la diffusion de documents scientifiques de niveau recherche, publiés ou non, émanant des établissements d'enseignement et de recherche français ou étrangers, des laboratoires publics ou privés. 


\title{
NUMERICAL SIMULATION OF THE CHARGE STATE EVOLUTION AND ENERGY LOSSES IN FEAVY ION BEAM-PLASMA INTERACTIONS
}

\author{
J.M. GUIHAUME( $\left.{ }^{1}\right)$, R. DEI-CAS, M.A. BEUVE and S. JOLY \\ Commissariat à l'Energie Atomique, Service de Physique et \\ Techniques Nucléaires. Centre d'Etude de Bruyères-le-Châtel. \\ F-91680 Bruyères-1e-Châtel, France
}

\begin{abstract}
Résumé - Un code numérique, de type Monte-Carlo, a été écrit afin d'analyser l'évolution de l'état de charge et de l'énergie d'un faisceau d'ions lourds traversant un plasma créé par laser. Nous présentons, tout d'abord, l'ensemble des processus physiques pris en compte lors de l'interaction, puis, traitons celle d'un faisceau de cuivre avec un plasma de carbone et avec un plasma d'aluminium.

Abstract - To analyse the charge state and energy evolutions of heavy ions travelling through a laser created plasma, a Monte-Carlo code has been written. A detailed account of the physical processes involved during the interaction is given here. The code is applied to the interaction of a $\mathrm{Cu}$-beam with a C-plasma and with an Al-plasma.
\end{abstract}

\section{1 - INTRODUCTION}

Recently, heavy ion beams have been considered as promising drivers for inertial-confinement fusion, therefore the processes involved during the slowing down of fast heavy ions in plasmas are of prime importance. This paper describes the numerical simulation code /1/ which has been developed to help us in the analysis of our experimental data $/ 2,3 /$.

Many physical processes, which are not precisely known, occur during the heavy ion beam-plasma interaction. Therefore, it is helpful, for data analysis, to have a guide describing the experiment as closely as possible. A Monte-Carlo technique was used to follow the history of many particles ; subsequently, the charge state distribution, the mean effective charge state, the energy distribution and the Coulomb scattering processes could be determined.

\section{2 - NUMERICAL SIMULATION CODE}

\section{1 - PLASMA MODEL}

Plasmas created by laser impact on a high atomic number target are not in Local Thermal Equilibrium (L.T.E), then Saha's equation, which gives each ion species population, can not be used and has to be replaced $/ 4$ / by a coronal ionization equation since the electron density satisfies :

$$
\mathrm{n}_{\mathrm{e}}\left(\mathrm{cm}^{-3}\right) \leq 3.10^{13} \mathrm{U}_{\mathrm{n}}^{3} \mathrm{~T}_{\mathrm{e}}^{1 / 2}
$$

where $T_{e}$ is the electron temperature $(e V)$, and $U_{n}$ the electron binding energy (eV) for target ions. For example, the coronal model will be valid for ions with $U_{n} 223$ eV and a plasma characterized by $\mathrm{T}_{\mathrm{e}}=200 \mathrm{eV}$ and $\mathrm{n}_{\mathrm{e}}=5.10^{18} \mathrm{~cm}^{-3}$.

(1) Present address : Centre d'Etudes de Limeil-Valenton, B.P. $n^{\circ} 27,94190$ VILLENEUVE-ST-GEORGES 
Instead of each collision process being balanced by its inverse collision process as in the L.T.E model, in the coronal model, the balance is between collisional ionization (and excitation) and radiative and dielectronic recombinations (and spontaneous decay). Moreover, it is assumed that the radiation escapes without interacting with the plasma (the optically thin approximation), and that the plasma free electron and ion velocities have a Maxwellian distribution with $\mathrm{T}_{i} \leq \mathrm{T}_{e}{ }$ Thus, in our simulation, the ion densities are deduced from a coronal model (valid for $\mathrm{T}_{\mathrm{e}} \in\left[10,10^{4}\right] \mathrm{eV}$ ) and the plasma target parameters ( $\mathrm{n}_{e}, \mathrm{~T}_{e}$ ) are deduced from a $1 \mathrm{D}$ Lagrangian code $12 /$. In the region of interest (a few $\mathrm{mm}$ in front of the target plane), the electron temperature is assumed to be constant and the density profile of the type :

$$
n_{e}(y, r)=4.2510^{19} \exp (-4.25 y) \exp \left(-\left(\frac{r}{0.25}\right)^{2}\right)
$$

where $\mathrm{y}$ is the plasma expansion direction along the laser line and $I$ the radial position.

\section{2 - ATOMIC PHYSICAL PROCESSES}

In the heavy ion beam-plasma interaction, many atomic physical processes modify the plasma and the beam characteristics. But, as the ion beam density is much less than the electronic and ionic plasma ones, during the interaction, the plasma is considered in a steady state. Moreover, for our experiment parameters $\left(n_{e}, T_{e}, \vec{V}_{i o n}\right)$, the average ion-ion distance within the beam remains much larger than the electron Debye length; the beam-target interaction can thus be reduced to a single ion-target one, neglecting collective aspects in a first approach /5/. In the experimental field of interest, the three-body recombination is negligible because of kinematical constraints 16/. On the other hand, excitation, de-excitation and multiple charge exchange processes were not taken into account as the relevant cross sections were not known.

The considered atomic physical processes are : electron and ion ionizations, bound-bound recombination (charge exchange), radiative and dielectronic recombinations, for which reliable, measured or calculated, cross. sections exist in the largest ranges of energy and charge state.

a) Electron ionization : $\mathrm{x}^{\mathrm{q}^{+}}+\mathrm{e}^{-} \rightarrow \mathrm{x}^{(\mathrm{q}+1)+}+2 \mathrm{e}^{-}$

The Lotz' formula $/ 7 /$ is chosen for the ionization cross section where the electron kinetic energy is replaced by the relative energy $\frac{1}{2} \mathrm{~m} \mathrm{~g}^{2}$, where $\vec{g}$ represents the relative velocity between the projectile ion $\left(\vec{v}_{1}\right)$ and the electron $\left(\vec{w}_{2}\right)$, and $m$ the relative mass $\left(m \simeq m_{e}\right)$ :

$$
\sigma_{i e}(g)=4.510^{-14} \sum_{i=1}^{N} q_{i} \frac{\log \left(\frac{l}{2} \mathrm{mg}^{2} / U_{i}\right)}{\frac{1}{2} \mathrm{mg}^{2} \cdot U_{i}}\left(\mathrm{~cm}^{2}\right)
$$

$U_{i}$ is the binding energy of the $q_{i}$ electrons of the $i^{\text {th }}$ shell among the $N$ considered shells ; $N^{I}=1$ for $\mathrm{H}-$ and $\mathrm{He}-$ like ions, $\mathrm{N}=2$ for $\mathrm{Li}-$ and $\mathrm{Ne}-$ like ions and $\mathrm{N}=3$ for the other species. The reaction rate $\alpha_{i e}$ is calculated for projectiles having a constant velocity $\vec{V}_{1}$ and interacting with a Maxwellian plasma defined by :

$$
\mathrm{f}_{2}\left(\overrightarrow{\mathrm{w}}_{2}\right)=\frac{\ell^{3}}{\pi^{3 / 2}} \exp \left(-\ell^{2} \mathrm{w}_{2}^{2}\right) ; \ell^{2}=\frac{\mathrm{m}}{2 \mathrm{KT} e}
$$

In our case, $v_{1}=v_{\text {the }}\left(V_{\text {the }}\right.$, thermal electron velocity) and the reaction rate has to be averaged over the electron distribution $f_{2}\left(\vec{W}_{2}\right)$ :

$\alpha_{i e}=\frac{2 \ell \exp \left(-l^{2} v_{I}^{2}\right)}{v_{1} \pi^{1 / 2}} \int_{g_{\min }}^{\infty} g^{2} \exp \left(-\ell^{2} g^{2}\right) \operatorname{sh}\left(2 l^{2} v_{1} g\right) \cdot \sigma_{i e}(g) d g$

where : $g_{\min }=\left(\frac{2 U_{i}}{m}\right) 1 / 2$ 


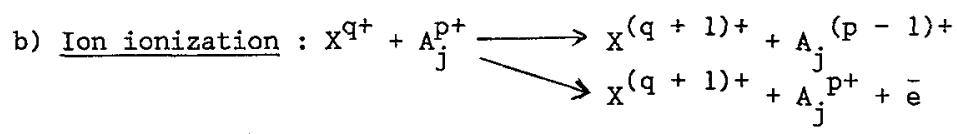

Electron loss cross section, due to collisions of the projectile with the plasma ions, is calculated in the binary encounter approximation (B.E.A) /8/ :

$$
\sigma_{i j}\left(v_{1}\right)=\sum_{n=1}^{N} \quad q_{n} \sigma_{i_{n} j}=\sum_{n=1}^{N}\left(q_{n} z_{j n}^{*^{2}} \pi e^{4} / U_{n}^{2}\right) G\left(v_{r}\right)\left(c^{2}\right)
$$

where $\sigma_{i_{n}}$ is the projectile ionization (for the $n$ shell) cross section by the $j$ plasma ion species $; q_{n}$ is the electron number in the $n^{\text {th }}$ shell, among the $N$ considered shells, having a binding energy $U_{n} ; G\left(V_{r}\right)$ is a tabulated function of the ratio $v_{1} / v_{e n}$, where $v_{\text {en }}$ is the mean electron orbital velocity of the $n^{\text {th }}$ shell. The effective charge $z_{j n}^{*}$ is defined from the Green, sellin and Zachor (G.S.Z) model /9/. In our case, $v_{1} \gg v_{\text {thi }}\left(V_{\text {thi }}\right.$, thermal ion velocity) and the reaction rate is given by :

$$
\alpha_{i j}=\sigma_{i j}\left(v_{1}\right) \cdot v_{1}\left(\mathrm{~cm}^{3} \cdot \mathrm{s}^{-1}\right)
$$

c) Bound-Bound recombination (charge exchange)

$$
\mathrm{X}^{\mathrm{q}+}+\mathrm{A}_{\mathrm{j}}^{\mathrm{p}^{+}} \rightarrow \mathrm{x}^{(\mathrm{q}-1)+}+\mathrm{A}_{j}(\mathrm{p}+1)+
$$

Capture of bound electrons by the ion projectile in the plasma ions is calculated in the Oppenheimer, Brinkmann and Kramers (O.B.K) approximation /10-13/. The electron capture of a $H$-like ion of charge $p$ and shell $k$ by an ion of mass $A$, energy $E$ and charge state $q$ on the shell $n$ is given by :

$\sigma_{n k}=a_{\text {chan }} \frac{1.1210^{-10}(\mathrm{pq})^{5}}{\mathrm{n}^{3} \mathrm{k}^{5}-\frac{\mathrm{E}}{\mathrm{A}}\left[\frac{\mathrm{p}^{2}}{2 \mathrm{k}^{2}}+\frac{\mathrm{q}^{2}}{2 \mathrm{n}^{2}}+10^{-5} \frac{\mathrm{E}}{\mathrm{A}}+\frac{\mathrm{A}}{1.610^{-5} \mathrm{E}}\left(\frac{\mathrm{p}^{2}}{\mathrm{k}^{2}}-\frac{\mathrm{q}^{2}}{\mathrm{n}^{2}}\right)^{2}\right]^{5}}$

with $a_{\text {chan }}=0.3$ for $E / A=1 \mathrm{MeV} / \mathrm{amu}$.

The total cross section is :

$$
\sigma_{\mathrm{qq}-1}=\sum_{\mathrm{n}=1}^{\infty} \sum_{k=1}^{\infty} \quad \mathrm{N}_{\mathrm{k}} \quad \sigma_{\mathrm{nk}} \quad\left(\mathrm{cm}^{2}\right)
$$

where $\mathrm{N}_{k}$ is the electron number in the $k$-shell. Then, as $v_{1} \gg v_{\text {thi }}$, the reaction rate is :

$$
\alpha_{\mathrm{qq}-1}=\sigma_{\mathrm{qq}-1} \cdot \mathrm{v}_{1} \quad\left(\mathrm{~cm}^{3} \cdot \mathrm{s}^{-1}\right)
$$

d) Radiative recombination : $\mathrm{x}^{\mathrm{q}^{+}}+\mathrm{e}^{-} \rightarrow \mathrm{x}^{(\mathrm{q}-1)+}+\mathrm{hv}$

Capture by the ion projectile of plasma free electrons by the radiative recombination process is calculated according to Menzel $/ 14 /$ and Spitzer $/ 15 /$. The cross section is calculated for H-like ions by the following formula, assuming a Gaunt factor of unity and replacing the kinetic electron energy by its relative energy $\frac{1}{2} \mathrm{mg}^{2}$ :

$$
\sigma_{\mathrm{RR}}(\mathrm{g})=\sum_{\mathrm{n}=1}^{\infty} 2.1110^{-22} \frac{\mathrm{hv}{ }_{1}}{\left(\frac{1}{2} \mathrm{mg}^{2}+\frac{\mathrm{hv}}{\mathrm{n}^{2}}\right)} \frac{\mathrm{hv}{ }_{1}}{\frac{1}{2} \mathrm{mg}^{2}} \cdot \frac{1}{\mathrm{n}^{3}}\left(\mathrm{~cm}^{2}\right)
$$

with $: h v_{1}=13.6 q^{2}(\mathrm{eV})$. 
The reaction rate is obtained by integrating over the electron distribution $f_{2}\left(\vec{W}_{2}\right):$

$$
\alpha_{R R}=\frac{2 l \exp \left(-\ell^{2} v_{1}^{2}\right)}{v_{1} \pi^{1 / 2}} \cdot \int_{0}^{\infty} g^{2} \exp \left(-\ell^{2} g^{2}\right) \cdot \operatorname{sh}\left(2 l^{2} v_{1} g\right) \cdot \sigma_{R R}(g) d g\left(\mathrm{~cm}^{3} \cdot s^{-1}\right)
$$

e) Dielectronic recombination $: \mathrm{x}^{\mathrm{q}^{+}}+\mathrm{e}^{-} \rightarrow\left(\mathrm{x}^{(\mathrm{q}-1)+}\right)^{* *} \rightarrow \mathrm{x}^{(\mathrm{q}-1)+}+\mathrm{hv}$

No general formulation is available, at this time, for this process and a constant value, believed to be an upper limit $/ 16 /$, has been assumed $: \alpha_{\mathrm{RD}}=10^{-11}\left(\mathrm{~cm}^{3} \cdot \mathrm{s}^{-1}\right)$.

f) Reaction rates : typical values

In the particular interaction of a Cu-beam (charge state $q$, energy $\mathrm{E}$ ) with an Al plasma (electronic temperature $\mathrm{T}_{e}$ ), we have calculated the reaction rates mentionned above. The Al-plasma is assumed to be in a coronal regime with $\mathrm{T}_{e}=250 \mathrm{eV}$ and $\mathrm{Al}^{9+}-\mathrm{Al}^{10+}-\mathrm{Al}^{11+}-\mathrm{Al}^{12+}$ ions were considered. Figures 1 to 3 give the rates "no" as a function of the incident ion energy or its charge state ; they show that ion-ion reactions will play the most important role.

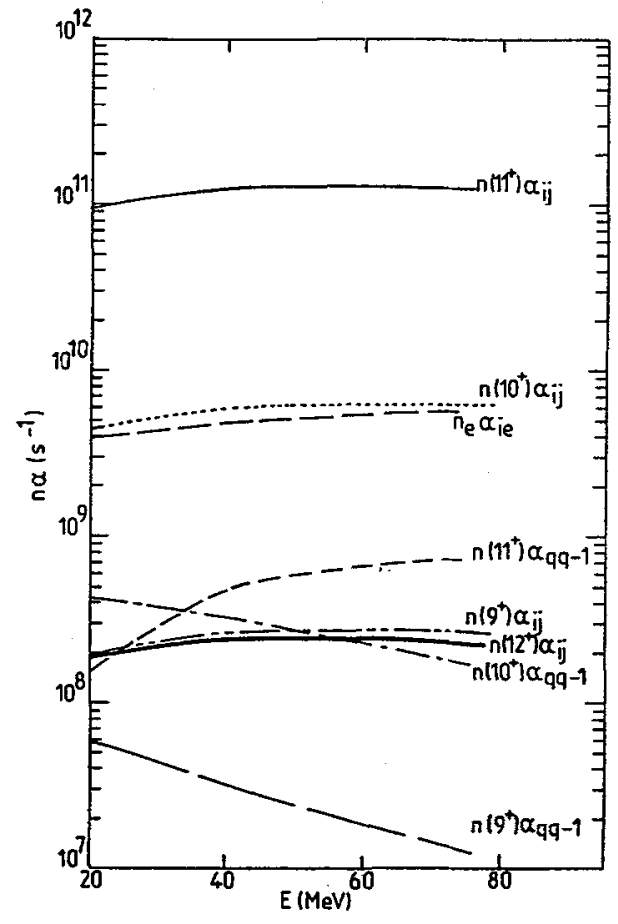

Fig. 1 - Reaction rates of the most probable atomic processes occuring during the interaction of $\mathrm{Cu}^{7+}$ ions with an Al-plasma $\left(\mathrm{T}_{\mathrm{e}}=250 \mathrm{eV}\right.$, $n_{e}=10^{18} \mathrm{~cm}^{-3}$ ) as a function of ion energy.

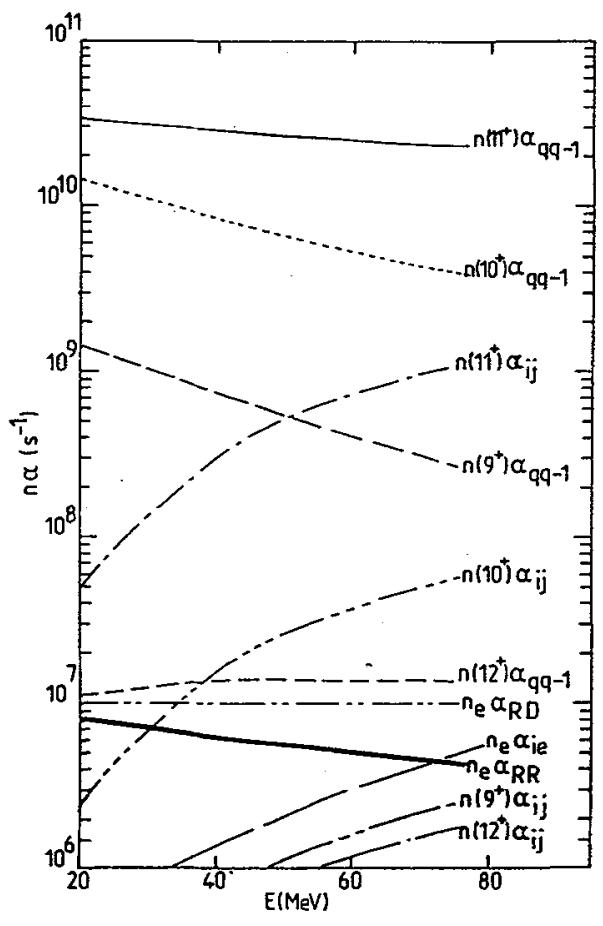

Fig. 2 - Refer to figure $\frac{1}{2} \dot{0}^{+}$
Reactions induced by $\mathrm{Cu}^{\text {. }}$

\section{3 - ENERGY LOSSES}

While the previously quoted atomic processes occur, the ion projectile slows down by excitation and ionization processes and transfers part of its energy to plasma ions, plasma free electrons and bound electrons. In the energy loss calculation, we introduce the effective charge state which is the instantaneous equilibrium charge state determined by the competition between ionization, charge exchange processes,... This effective charge is calculated along the ion path within the plasma using a random technique for the electron loss and the capture branching ratios. 


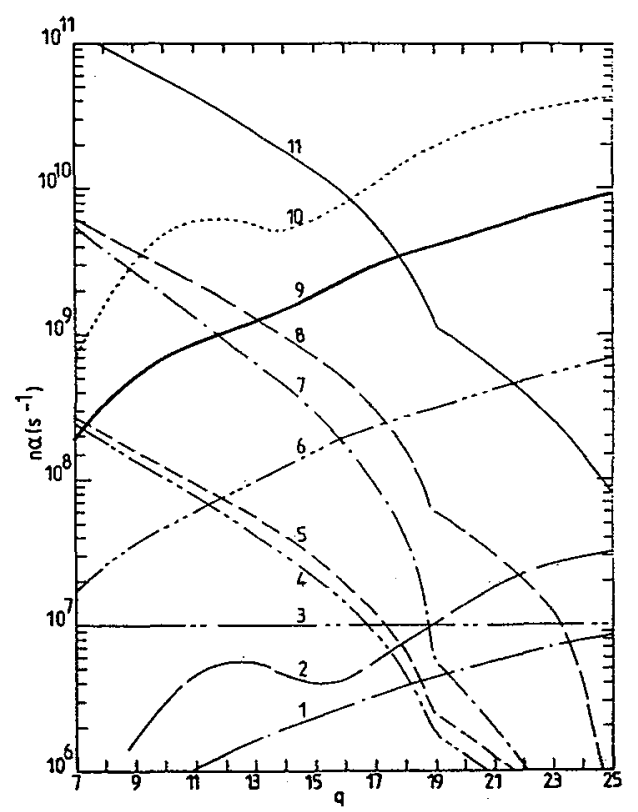

Fig. 3 - Interaction of $64 \mathrm{MeV} \mathrm{Cu-ions} \mathrm{with} \mathrm{an} \mathrm{Al-plasma}$ $\left(T_{e}=250 \mathrm{eV}, \mathrm{n}_{e}=10^{18} \mathrm{~cm}^{-3}\right)$ : reaction rates versus ion charge state $\mathrm{q}$. Curves :

1) $\mathrm{n}_{\mathrm{e}} \alpha_{\mathrm{RR}}$; 2) $\mathrm{n}\left(12^{+}\right) \alpha_{\mathrm{qq}-1}$; 3) $\mathrm{n}_{\mathrm{e}} \alpha_{\mathrm{RD}}$

4) $\mathrm{n}(12+) \alpha_{i j}$; 5) $\mathrm{n}\left(9^{+}\right) \alpha_{i j}$; 6) $\mathrm{n}\left(9^{+}\right) \alpha_{q q-1}$

7) $\mathrm{n}_{\mathrm{e}} \alpha_{\mathrm{ie}}$; 8) $\mathrm{n}\left(10^{+}\right) \alpha_{\mathrm{ij}}$; 9) $\mathrm{n}\left(10^{+}\right) \alpha_{\mathrm{qq}-1}$

10) $\mathrm{n}\left(11^{+}\right) \alpha_{\mathrm{qq}-1}$; 11) $\mathrm{n}\left(11^{+}\right) \alpha_{\mathrm{ij}}$.

a) Energy loss on bound electrons

* The Bethe's formula (valid for $\mathrm{E} / \mathrm{A} \geq 0.5 \mathrm{MeV} / \mathrm{amu}$ ), including the so-called shell corrections in order to extend its validity, is used at large velocity where the mean excitation energy $\tilde{I}_{j}$ for ions having more than four bound electrons is taken from Garbet's work /17/ :

$\left(\frac{-d E}{d x}\right)_{B}=2.3710^{-10} \frac{A}{E} q^{2} \cdot \sum_{j} n_{j}\left(Z_{c}^{-Z_{j}}\right)\left[\log \left(\frac{2.210^{-3} E}{A \tilde{I}_{j}}\right)-\sum_{i=0}^{4} a_{i}\left(\log \frac{10^{-3} E}{A}\right) i(e V / c m)\right.$

where $A$ is the ion projectile atomic mass, E its energy, $z_{j}$ the ionic species $j$ charge state, $n_{j}$ its density, $z_{c}$ the ion plasma atomic number. The $a_{i}$ coefficients are tabulated /18/.

* At low-projectile velocity, for ion charge state $q$ such as $q<z_{c}$, the Sudden Impulse Approximation is assumed :

$$
\left.\left(\frac{-d E}{d x}\right)_{S I A}=2.2210^{-15}\left(\frac{E}{A}\right){ }^{1 / 2} q^{2} \sum_{j} n_{j}\left(z_{c}-z_{j}\right) \frac{1}{E_{j n}}<\frac{1}{P}\right\rangle_{j n}(e V / c m)
$$

where $E_{j n}$ is the binding energy of the last occupied shell and $\left\langle\frac{1}{\mathrm{P}}\right\rangle_{j n}=2 \mathrm{~J}$ jn $(0)$; Compton profiles $\mathrm{J}_{\mathrm{jn}}(0)$ are tabulated /19/.

* If $q$ satisfies the inequality : $q>\left(137 \frac{V_{1}}{c}\right)^{3}$, the Linhard, Scharff, Schiott formula /20/ is used at low-projectile velocity : 


$$
\left(\frac{-d E}{d x}\right)_{\text {LSS }}=C_{\text {LSS }}(E)^{1 / 2}(\mathrm{eV} / \mathrm{cm})
$$

where $C_{\text {LSS }}$ depends on many target and projectile parameters.

b) Energy loss on free electrons

A general formulation, based on a Born-Random-Phase-Approximation model, valid in the whole velocity range, has been given by Maynard and Deutsch /21/ :

$$
\left(\frac{-d E}{d x}\right)_{M D}=2.3710^{-10} q^{2} \frac{A}{E} n_{e} \Psi(u) \frac{u^{4}+0.482}{u^{2}+1.5} \log \left(\frac{2.110^{3}}{b_{\min }}\left(\frac{T_{e}}{n_{e}}\right)^{1 / 2}\right)(\mathrm{eV} / \mathrm{cm})
$$

with : $u=\frac{v_{1}}{v_{\text {the }}}, \Psi(u)=\operatorname{erf}(u)-\frac{2 u}{\pi^{1 / 2}} \exp \left(-u^{2}\right)$ and $b_{\min }=\operatorname{Max}\left(\frac{q e^{2}}{m\langle g\rangle^{2}} \frac{h}{m\langle g\rangle}\right)$

c) Energy loss on ions

As $V_{1} \gg V_{\text {thi }}$, we use a classical expression formulated by Maynard /22/ following Mehlorn /23/ and Jackson $/ 24 /$ works. For an ionic species $j$, the stopping power is :

$$
\left(\frac{-d E}{d x}\right)_{M_{j}}=1.2910^{-13} q^{2} \frac{A}{E} \frac{{ }_{j} z_{j}^{2}}{A_{P}} \Psi\left(u^{\prime}\right) \log \left(\frac{7.0310^{9} A_{P} E}{\left(A+A_{P}\right) q_{j}}\left(\frac{T_{e}}{n_{e}}\right)\right)(e V / c m)
$$

with $u^{\prime}=\frac{V_{1}}{V_{t h i}} ; z_{j}$ is the ionic species $j$ charge state and $A_{p}$ the ion plasma atomic mass.

The contribution of plasma ions is very small if E/A>50 keV/amu, and can generally be neglected.

\section{4 - COULOMB SCATTERING}

The ion projectiles moving through the plasma are scattered by electrons (sçattering coefficient $\left\langle\left(\Delta V_{1}\right)^{2}\right\rangle_{\text {e }}$ and by every ion $j$ species $\left(\left\langle\left(\Delta V_{1}\right)^{2}\right\rangle_{j}\right)$; the resulting scattering coefficient is assumed to be given by :

$$
\left\langle\left(\Delta v_{1 \underline{1}}\right)^{2}\right\rangle=\left\langle\left(\Delta V_{1 \underline{1}}\right)^{2}\right\rangle_{e}+\sum_{j}\left\langle\left(\Delta V_{1}\right)^{2}\right\rangle_{j}
$$

where $\left\langle\left(\Delta \mathrm{v}_{1}\right)^{2}\right\rangle$ is given by Spitzer $/ 25 /$

From this expression, one can calculate the Coulomb scattering time $\tau_{\operatorname{CS}}=\left\langle\left(\Delta V_{1}\right)^{2}\right\rangle / v_{1}^{2}$, and the variation of the scattering cone angle d $\theta$ after a path de inside the plasma $/ 2 /:$

$$
\mathrm{d} \theta=\left(\frac{\left\langle\left(\Delta \mathrm{v}_{1}\right)^{2}\right\rangle \mathrm{d} \ell}{\mathrm{v}_{1}^{3}}\right) 1 / 2
$$

$d \Theta=3.6110^{-7} \frac{q}{E}(d \ell)^{1 / 2}\left[n_{e}(\Phi(u)-G(u)) \log \Lambda_{e}+\sum_{j} n_{j} z_{j}^{2}\left(\Phi\left(u^{\prime}\right)-G\left(u^{\prime}\right)\right) \log _{j} \Lambda^{1 / 2}\left(\mathrm{rad}^{\prime}\right)\right.$

where : $\Phi(\mathrm{x})=\operatorname{erf}(\mathrm{x})$ and $\mathrm{G}(\mathrm{x})=\left(\Phi(\mathrm{x})-\mathrm{x} \Phi^{\prime}(\mathrm{x})\right) / 2 \mathrm{x}^{2}$

$\log \Lambda_{e}=\frac{u^{4}+0.482}{u^{2}+1.5} \log \left(\frac{2.110^{3}}{b_{\min }}\left(\frac{T_{e}}{n_{e}}\right)^{1 / 2}\right)$

$\log \Lambda_{j}=\log \left(\frac{7.0310^{9} A_{p} E}{\left(A+A_{p}\right) Z_{j}}\left(\frac{T_{e}}{n_{e}}\right)^{1 / 2}\right)$ 
Figure 4 shows de as a function of energy and charge state of the projectile travelling, during $10^{-12} \mathrm{~s}$, through an Al-plasma with $\mathrm{T}_{\mathrm{e}}=250 \mathrm{eV}$ and $\mathrm{n}_{\mathrm{e}} \in\left[10^{17}, 10^{19}\right] \mathrm{cm}^{-3}$. In all cases, d $\mathrm{is}^{-}$ very small, but this scattering cannot be neglected. Indeed, our detector (an ionographic tube), located $2 \mathrm{~m}$ away from the interaction region, could observe this effect because of the long distance.

\section{5 - SIMULATION TECHNIQUE}

The code calculates charge state, energy and ion projectile trajectory evolutions within. the plasma during the interaction. Ion projectiles are tracked in a cartesian coordinate system, their history being evaluated by statistical processes of Monte-Carlo type. Since, the beam-target interaction can be reduced to an ion-target one, the calculation explained further on has to be repeated for each ion projectile.

At the plasma entrance (and after every collision), reaction rates are calculated which define an average total relaxation time $\tau$ and a charge changing probability $p(t)=1-e^{-t / \tau} ;$ the collision time is then determined by a random number between $\tau / 10$ and $10 \tau$. The total energy loss and the Coulomb scattering being taken into account, one can integrate the ion trajectory ; at each integration step, if the scattering cone angle d $\theta$ is larger than a minimum value, a random choice for this cone angle is made (between $O$ and $2 \pi$ ) to define new conditions for the velocity vector. With these new energy and direction values, reaction rates are calculated again and the effective charge is evaluated using a random process for the atomic reaction branching ratios. This procedure is repeated until the ion leaves the plasma. Then, the ion trajectory is integrated through a Thomson parabola spectrometer, combining magnetic and electric fields, until the ion reaches the ionographic tube.

\section{3 - NUMERICAL RESULTS}

The interactions of a Cu-beam with an Al-plasma, and of a Cu-beam with a C-plasma, were investigated. In both cases, to minimize statistical fluctuations and to reduce calculation time, the projectile initial bunch contained 1000 particles. For initial values, our study domain was :

$q_{0}(\mathrm{Cu})=7 ; E_{0}(\mathrm{Cu}) \in[50,125] \mathrm{MeV} ; \mathrm{T}_{e} \in[150,300] \mathrm{eV} ; \overline{\mathrm{n}_{\mathrm{e}} \mathrm{l}} \in\left[5.10^{16}, 10^{19}\right] \mathrm{cm}^{-2}$.

3.1 - CHARGE STATE DISTRIBUTION

Whatever the initial values are, we find for both interactions that the $N$ initial charge states $q_{0}$ become, at the plasma exit, a Gaussian distribution $\left(N_{i}, q_{i}\right)$ :

$$
N_{i}=\frac{N}{\sigma(2 \pi)^{1 / 2}} \quad \exp \left(-\frac{1}{2}\left(\frac{q_{i}-\bar{q}}{\sigma}\right)^{2}\right)
$$

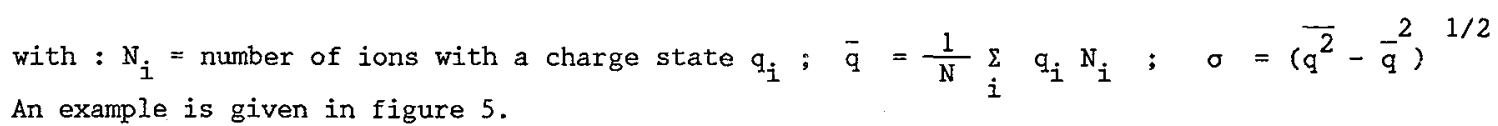

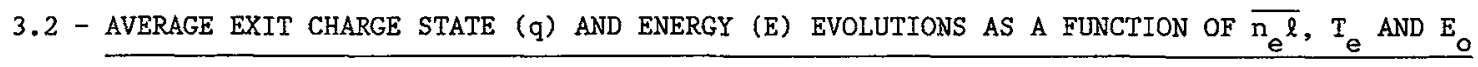

Figures 6 to 9 present out the most important results of this study.

- The average charge state $\bar{q}$ increases with the plasma electronic temperature (therefore, with the plasma ionization state) and with the linear electronic density ; its variation as a function of $E_{0}$ becomes significant only for high linear densities.

- The average energy $\vec{E}$ decreases slowly as a function of $\overline{n_{e} \cdot l}$ until $\overline{n_{e} \cdot l} 25.10^{18} \mathrm{~cm}^{-2}$, a point where the energy loss begins to increase ; moreover, this energy loss is inversely proportional to the electronic temperature. 


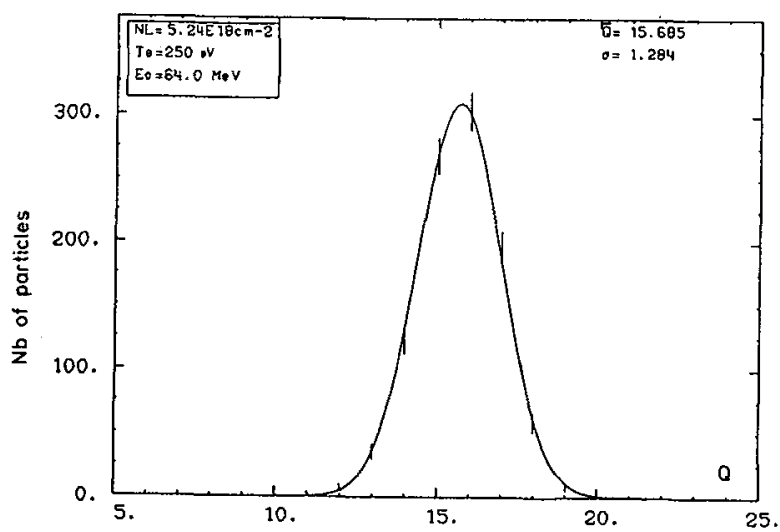

Fig. 5 - Charge distribution following the interaction of $\mathrm{Cu}^{7+}$ ions (energy $\mathrm{E}_{0}=64 \mathrm{MeV}$ ), with an Al-plasma $\left(\mathrm{T}_{\mathrm{e}}=250 \mathrm{eV} ; \mathrm{n}_{\mathrm{e}} \ell=5.2410^{18} \mathrm{~cm}^{-2}\right)$.
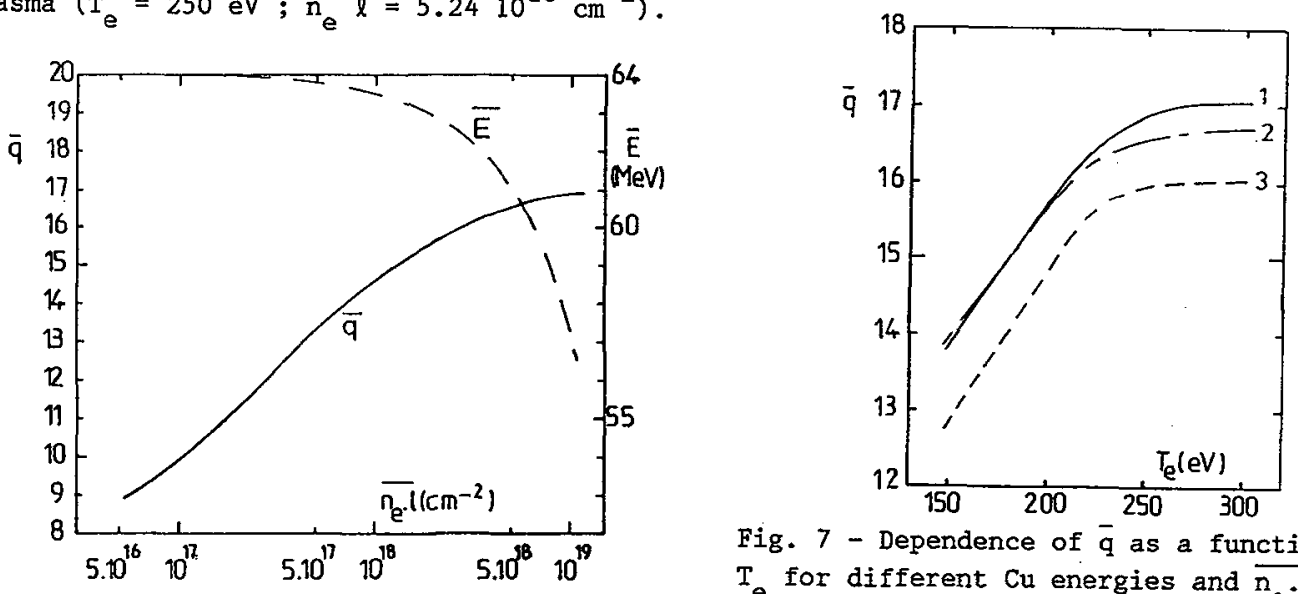

Fig. 7 - Dependence of $\bar{q}$ as a function of $T_{e}$ for different $C u$ energies and $\overline{n_{e^{+l}}}$ C-plasma conditions.

Fig. 6 - Dependence of $\bar{q}$ and $\overline{\mathrm{E}}$ as a function of $\overline{n_{e} \cdot l}$ for the interaction of $\mathrm{Cu}$ ions $\left(E_{0}=64 \mathrm{MeV}\right)$ with a $\mathrm{C}$-plasma $\left(\mathrm{T}_{\mathrm{e}}=250 \mathrm{eV}\right)$.

1) $\mathrm{E}_{\mathrm{o}}=64 \mathrm{MeV} ; \mathrm{n}_{\mathrm{e}}=5.2410^{18} \mathrm{~cm}^{-3}, \ell=1 \mathrm{~cm}$

2) $\mathrm{E}_{\mathrm{o}}=64 \mathrm{MeV} ; \overline{\mathrm{n}_{\mathrm{e}} \cdot \mathrm{l}}=5.2410^{18} \mathrm{~cm}^{-2}$

3) $\mathrm{E}_{\mathrm{o}}=50 \mathrm{MeV} ; \overline{\mathrm{n}_{e^{\cdot l}}}=5.2410^{18} \mathrm{~cm}^{-2}$

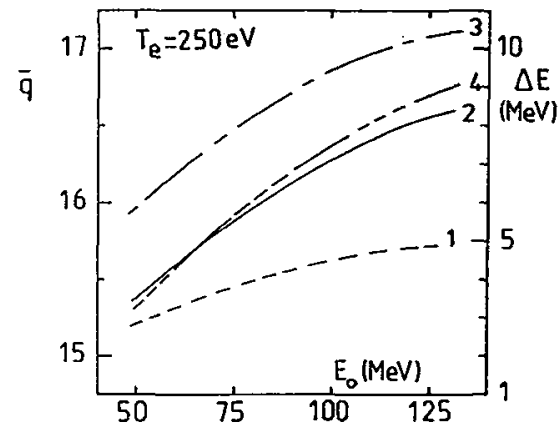

Fig. 8 - Dependence of $\bar{q}$ and energy loss $\triangle \mathrm{E}$ as a function of $\mathrm{Cu}$ energy $E_{0}$ for different Al-plasma linear densities. $\overline{n_{\overline{\mathrm{e}} \cdot l}}=5.2410^{18} \mathrm{~cm}^{-2}:$ 1) $\left.\Delta \mathrm{E} ; 2\right) \overline{\mathrm{q}}$ $\left.\left.\overline{n_{e} \cdot l}=1.0510^{19} \mathrm{~cm}^{-2}: 3\right) \Delta E ; 4\right) \bar{q}$

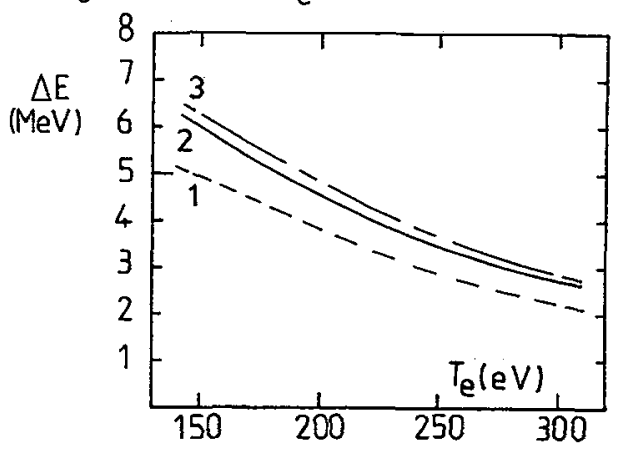

Fig. 9 - Dependence of $\Delta \mathrm{E}$ as a function of $\mathrm{T}_{\mathrm{e}}$ for different $\mathrm{Cu}$ energies and Al-plasma linear densities.
1) $\mathrm{E}_{0}=50 \mathrm{MeV} ; \overline{\mathrm{n}_{e^{+l}}}=5.2410^{18} \mathrm{~cm}^{-2}$
2) $E_{0}=64 \mathrm{MeV} ; \overline{n_{e} \cdot l}=5.2410^{18} \mathrm{~cm}^{-2}$
3) $\mathrm{E}_{\mathrm{o}}=64 \mathrm{MeV} ; \mathrm{n}_{\mathrm{e}}=5.2410^{18} \mathrm{~cm}^{-3}, \ell=1 \mathrm{~cm}$ 


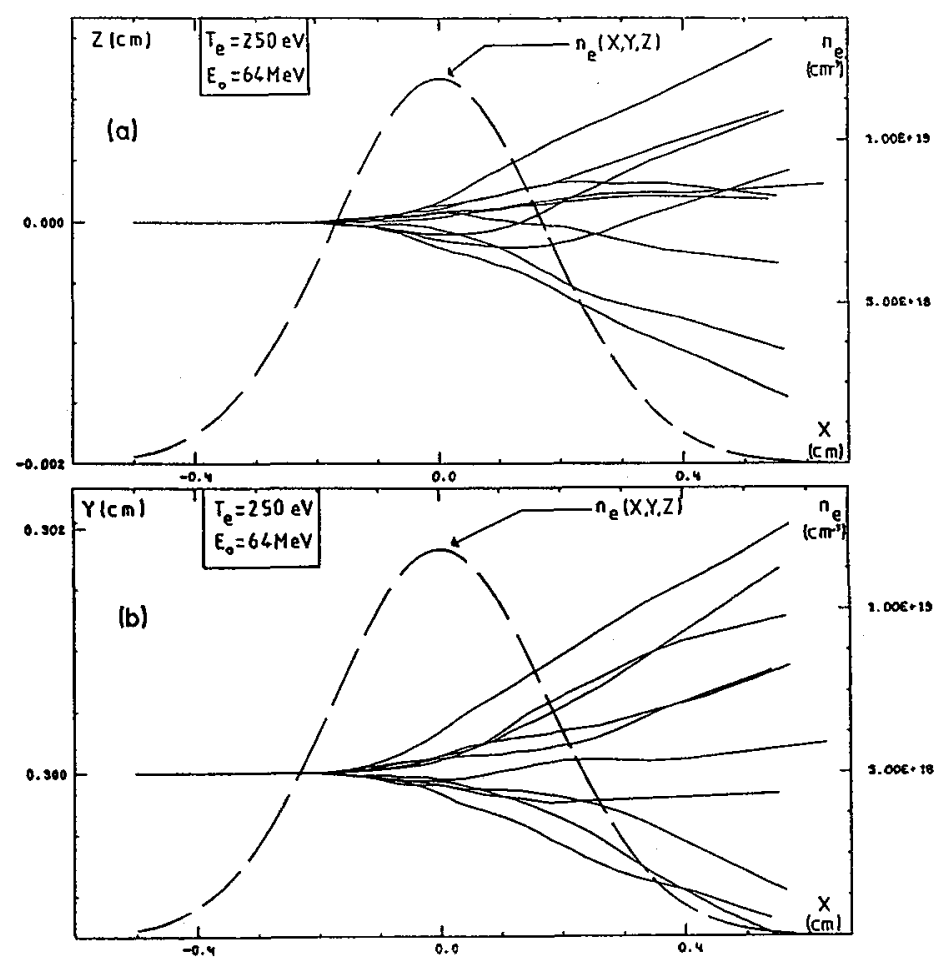

Fig. 10 - Interaction of $10 \mathrm{Cu}$ ions with an Al-plasma : trajectories in a plane normal to the laser direction (a) and in a plane containing the laser direction (b).
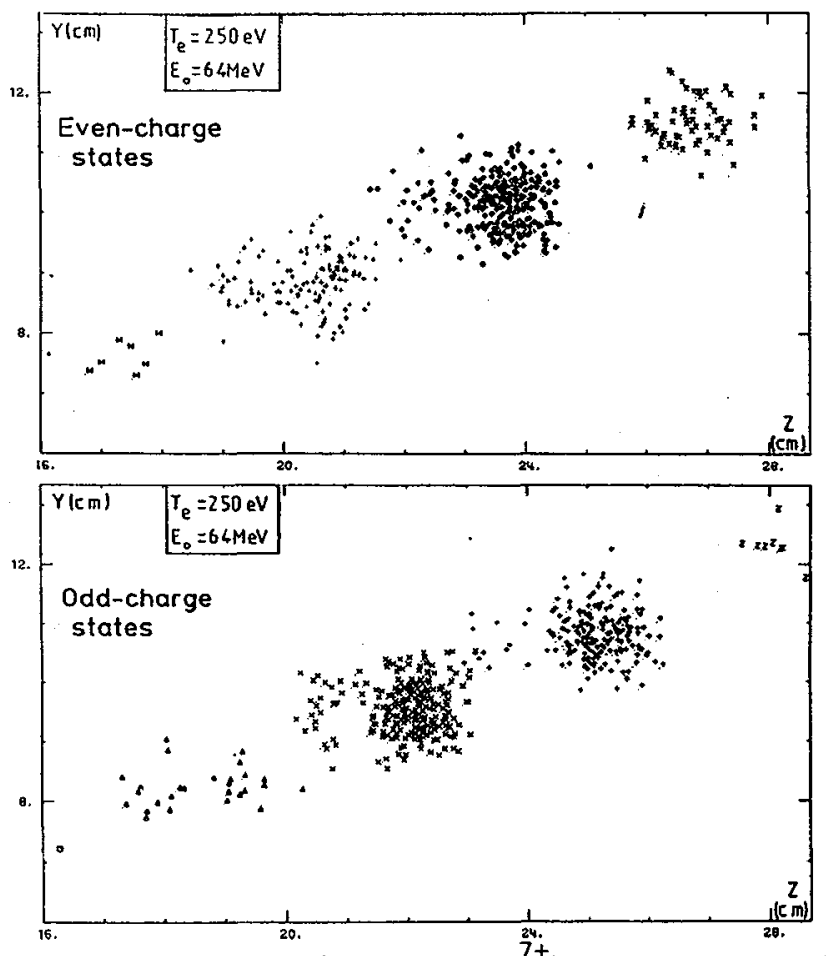

Fig. 11 - Spatial distribution of 1000 (initially $\mathrm{Cu}^{7+}$ ) ions after the interaction with an $\mathrm{Al-}$ plasma. at the end of the Thomson spectrometer. $\mathrm{A}: \mathrm{Cu}^{11+} ; \mathrm{Cu}^{12+} ; \Delta: \mathrm{Cu}^{13+} ;+: \mathrm{Cu}^{14+} ;$ $\mathrm{X}: \mathrm{Cu}^{15+} ; \Delta: \mathrm{Cu}^{16+} ; \uparrow: \mathrm{Cu}^{17+} ; \mathrm{X}: \mathrm{Cu}^{18+} ; \mathrm{Z}: \mathrm{Cu}^{19+}$. 


\section{3 - SPATIAL DISTRIBUTION}

Figures 10 and 11 show the ion trajectories within the plasma and the spatial distribution on the detector plane, respectively. The Coulomb scattering has a small effect (average scattering cone angle less than $10^{-4}$ rad for one integration step) but cannot be neglected in our density range ; indeed, when the ions moved through the Thomson parabola spectrometer, this scattering process induces a mixing of different ionic species $\left(\mathrm{N}_{i}, \mathrm{q}_{i}\right)$.

\section{4 - CONCLUSION}

These results were tested against large variations in the cross sections ; dividing or multiplying the ion- and e- ionization cross sections $\left(\sigma_{i j}, \sigma_{i e}\right)$ and the charge exchange one $\left(\sigma_{q q-1}\right)$ by a factor of 2 would shift $\bar{q}$ by less than one charge state and $\overrightarrow{\mathrm{E}}$ by less than $2 \%$. A comparative study with Maynard (private communication) and Nardi and Zinamon /26/ calculations has been carried out ; there is a good qualitative agreement for the calculated dependences of the parameters $(\bar{q}$, $\bar{E})$. To improve our estimates, the possibility of including multiple charge exchange, excitation and de-excitation processes has been considered. However, only the experimental results will allow us to estimate, with the best accuracy, our model validity, the approximations we made and the numerical techniques we used.

The authors are grateful to $\mathrm{Cl}$. DEUTSCH for continuous support of this work and for stimulating discussions.

\section{REFERENCES}

/1/ J.M. GUIHAUME, Thesis (Orsay 1986), Interaction d'un faisceau d'ions lourds avec un plasma créé par un laser à $\mathrm{CO}_{2}$. Mise au point d'un tube ionographique et simulation de l'expérience.

/2/ R. DEI-CAS et al., J. Physique 11 (1983) 179

/3/ R. DEI-CAS, 2th Int. Workshop on Atomic Physics for Ion Fusion R.A.L., Chilton, Sept. 11-16 (1984)

/4/ T.F. STRATTON, Plasma Diagnostic Technics (chap.8), Academic Press (1965)

/5/ C. DEUTSCH, Annales de Physique 11 (1986) 1

/6/ D. BAILEY, Y.T. LEE, R.M. MORE, J. Physique, 44, C8 (1983) 149

/7/ W. LOTZ, Zeitschrift fur Physik 206 (1967) $205 ; 216$ (1968) $241 ; 220$ (1969) 466

/8/ J.H. MCGUIRE, P. RICHARD, Phys. Rev. A8, 1374 (1973)

19/ A.E.S. GREEN, D.L. SELLIN, A.S. ZACHOR, Phys. Rev. 184 (1969) 1

$/ 10 /$ H.C. BRINKMAN, H.A. KRAMERS, Proc. Acad. Sci. Amsterdam 33 (1930) 973

/11/ R.M. MAY, Phys. Rev. A136 (1964) 599

/12/ K. OMIDVAR, Phys. Rev. Al53 (1967) 121

/13/ F.T. CHAN, J. EICHLER, Phys. Rev. Letters 42 (1979) 58

/14/ D.H. MENZEL, Ap. J. 85 (1937) 330

/15/ L. SPITZER, Jr, Astrophys. J. 107 (1948) 6

/16/ E. NARDI, Z. ZINAMON, Phys. Rev. Letters 49 (1982) 1251

/17/ X. GARBET, Thesis (Orsay, 1984)

/18/ H.H. ANDERSEN, J.F. ZIEGLER, Stopping and ranges of ions in matter, Pergamon, New York (1977)

/19/ F. BRIGGS, L.B. MENDELSOHN, J.B. MANN, At. Data and Nucl. Data Tables 16 (1975) 201

/20/ J. LINDHARD, M. SCHARFF, H.E. SCHIOTT, Dan. Videnskab. Selsmab Mat. Fy Medd. 33 (1963) 14

/21/ G. MAYNARD, C. DEUTSCH, J. Physique 46 (1985) 113

/22/ G. MAYNARD, Thesis (Orsay, 1982)

123/ T.A. MEHLORN, Report SAND 80-0038 (Sandia Laboratories) (1980)

124/ J.D. JACKSON, Classical Electrodynamics, p. 643, Ed. John WILEY and Sons (1975)

/25/ L. SPITZER, Jr, Physics of Fully Ionized Gases (2d edition), Ed. John WILEY and Sons (1962)

/26/ E. NARDI, Z. ZINAMON, J. Physique 44 (1983) C8-93 